\title{
Hydroponic Farming in Indian Hotels
}

\author{
Pulla Suresh, Sam Nirmal, Arpan Roy \\ Institute of Hotel Management, Hyderabad
}

\begin{abstract}
Hydroponics farms have become a new trend in the Agricultural sector, especially with the growing needs of food and also because of the limited resources. The purpose of the research project was to gain knowledge about the modern Farming Method. The findings of the research suggest that in about 5-10 years of time the hydroponic business is eyed to increase about 200\%-300\%compared to the present situation. The food products produced by Hydroponics method are both nutritious and organic. The limited use of resources in hydroponic farming makes this method the tool for future sustainability. The complete analysis of the research has been made by using 2 basic research tools .One is an online survey, conducted to collect the information regarding people views about Hydroponics.
\end{abstract}

The other tool was an interview with a local Hydroponic Grower.

\section{Objectives}

The present research planned to explore the following objectives:

- To know the working principle of hydroponic

- To know the future of hydroponics in India

- To know the effect of hydroponics on hotel industry

- To know the benefits of growing in house

- To setup the hydroponic farm in Hotel

- To know the environmental benefits of hydroponics

\section{INTRODUCTION}

Hydroponics is a system of agriculture that utilizes nutrient-solvent rather than soil for plant nourishment and growth. It can also be defined as a method in wherein plants are grown in a liquid nutrient solution with or without the use of artificial media require pesticides, require less water and space than the traditional agricultural systems. Plants grown in soil and plants grown in a Hydroponics system do not need to develop extensive root structures to search for nutrients due to this it is easy to test and adjust $\mathrm{pH}$ levels(the crucial element to sustain plant life.

Plants need minimal energy to acquire nutrients from the roots. Where as in Hydroponics method, plants are raised in an inert and perfectly $\mathrm{pH}$ balanced growing medium where the energy saved by the roots is spent on flower and fruit production. In Hydroponics method, the root system of the plant is supported with an inert medium such as perlite,Rockwool, clay pellets, peat moss, or vermiculite. The nutrient solution provided to the plant is also provided or accessed with proper oxygen facility which is very essential for the plant growth.

\section{HYDROPONICS}

\section{$>$ Definition}

The word Hydroponics is taken from the Greek language where Hydro means"water"and Ponics means "toil", "labor".It is a method of cultivation or growing of plants without soil. The word Hydroponics is just a century old the method is being practiced for a very long time the hanging gardens of Babylon, the floating gardens of the Aztecs of Mexico, are the examples of Hydroponic culture. This method of farming is a niche market gaining popularity in urban, customized agriculture setup.

\section{Science behind Hydroponics}

The working principle or the science behind the hydroponic method can be easily determined by the science through which plants obtain food and grow. It has been proven scientifically that plants grow through a process called Photosynthesis, in which they use sunlight and a chemical pigment present in them called Chlorophyll to convert the glucose are further converted into fibers allowing the plants to grow. The pigment chlorophyll acts as a catalyst in the reaction as it enhances the occurrence of the reaction. If observed carefully, the use of soil is not determined in the growth of the plants because soil primary role of to provide strength to the plant by strengthening by this it can be clearly understood that for the growth of the plant soil is not important. The plant needs proper nutrition and water, soil is the best way to obtain nutrition, but if the plants could get those nutrients from other source, they would still survive. This is the basic principle behind Hydroponics. The plants that are grown by Hydroponics dip their roots directly into the nutrient based water solvents rather than absorbing from the soil making the roots job easier. This is the reason for the shorter root system of these plants; this shorter root system enables the plant to divert their energy usage from absorbing nutrients from soil into growth of the leaves and the stem.

\section{$>$ Hydroponics Market}

The Global Hydroponics Market was valued at USD 8.1 billion in 2018.Europe being the largest geographic segment of the market studied and accounted for a share of around $47.3 \%$ of the overall market. It has been promoted by the various governments and non-governmental. 
Organizations for its benefits in terms of food security. A lot of Research \& Development activity is being carried out globally to reduce the cost involved in technology. Europe is traditionally the largest market that is implanting advanced techniques in hydroponics horticulture. Asia-Pacific is the second largest market for hydroponics are expected to rise steadily, The highest and the biggest demand in hydroponics is for tomatoes as it accounts for $30.8 \%$ of share in the global market, during 2018.

\section{$>$ Present Hydroponic Adopters}

- In Tokyo to feed the citizens while preserving land, the country has implemented hydroponic rice production.

- A company called Organitech has been growing crops using hydroponic systems.

- They grow large quantities of bananas, berries, citrus fruits, and other fruits which cannot be normally grown in Israel's' climate.

- In Guangzhou, China, 14 hydroponic tanks have been installed on a rooftop measuring $1,600 \mathrm{ft}^{2}$, producing many pounds of vegetables per annum . The tanks are part of a study that is trying to show residents and developers in the Chinese city that their rooftops have the potential to supply a gentle supply of vegetables that may even be cheaper than store-bought alternatives.

- Bermudians have turned to hydroponic systems, which take around $20 \%$ of the land usually required for crop growth. This allows the people in island to produce without the expense throughout the year.

- Places like Alaska and Russia, where growing seasons are shorter, use hydroponic greenhouses, where light and temperature are often controlled to supply higher crop yields.

\section{$>$ Future of Hydroponics in India}

The cost of produce coming out of a hydroponic yield is much higher in India than the cost of one traditional unit. However, with constant innovation and adoption of newer techniques of growing, the cost differential is reducing. So, we'll see progressive farmers adopting the technologies faster in coming years. But still the large part of farming in India will remain traditional due to cost considerations and also technology limitations. The current trend for the hydroponically farming is only limited to metropolitan and cosmopolitan cities. Most of these plants grown are micro greens. Just because the cost of production and the cost of operation is high, people in India are not much into Hydroponically thing. With increase in population, if the farmers in India opt for this type of farming then this could really be a start of the new green revolution. There will be many more advantages of hydroponic farming especially in India not just because of the development but also because of the need. There is a scarcity of water and agricultural land in the world and particularly in India, by using this method we can alleviate the environment in terms of Air quality index, water scarcity, hunger. The development or the spread of Hydroponics across India is truly a dream to accomplish and if this happens then it will truly be an Agricultural Revolution. The change in farming concepts will happen in near future in India, however, in the current scenario, working on hydroponics farming is underway.

Individuals as well as corporate are assembling for this ground-breaking farm methodologies.

\section{HYDROPONICS IN HOTEL INDUSTRY}

The hotel industry has adopted the use of hydroponically produced products and the method more than a decade especially in kitchens and restaurants. The demand for these products Future of Hydroponics in India. The cost of produce coming out of a hydroponic yield is much higher in India than the cost of one traditional unit. However the

Innovation and adoption of newer techniques is reducing the cost. So, we'll see progressive farmers adopting the technologies faster in coming years. But still the large part of farming in India will remain traditional due to cost considerations and also technology limitations. The current trend for the hydroponically farming is only limited to metropolitan and cosmopolitan cities. Most of these plants grown are micro greens. Just because the cost of production and the cost of operation is high, people in India are not much into Hydroponically thing.

With increase in population, if the farmers in India opt for this type of farming then this could really be a start of the new green revolution. There will be many more advantages of hydroponic farming especially in India not just because of the development but also because of the need. There is a scarcity of water and agricultural land in the world and particularly in India, by using this method we can alleviate the environment in terms of Air the development or the spread of Hydroponics across India is truly a dream to accomplish and if this happens then it will truly be an Agricultural Revolution. The change in farming concepts will happen in near future in India, however, in the current scenario, working on hydroponics farming is underway. Individuals as well as corporate are assembling for this ground-breaking farm methodologies. Hydroponics in the hotel industry is being considered as the farming for the future already and there are many organizations arising to coupe up with the demand of the food and also the cash in the Profits.

\section{USE OF HYDROPONICS IN A HOTEL}

Hydroponics allows the user to not only cultivate food crops (vegetables and fruits) but also varieties of exotic flowers and fishes (aquaponics). Therefore there are various areas in a hotel industry wherein the products cultivated or produced by this method are encouraged. RESTAURANTS - Products like fruits, vegetables, micro greens, fishes, edible flowers, etc.are generally used in the kitchens of a hotel. Lettuce, micro greens, edible flowers are among those products which require a standard appearance and nutritive value to be served. 


\section{USE OF HYDROPONICS IN A HOTEL}

Thus hotels are now looking towards this method to attain the required standards, because hydroponic does not only produce nutritious food but the crop also has a quick and greater yield cycle.

Products are used for garnishing of food, cooking, Display of

$>$ Farm to table: Hydroponic farms within the hotel provide the farm to table concept to the customers.

$>$ The sole purpose of this concept is to provide the customers with utmost fresh and nutritious products and providing them the experience of the farm as well.

$>$ Fresh produce: Attaining a good dish is important for a restaurant to sustain its business.

$>$ For this, the chef must use the products of utmost quality.

$>$ In house hydroponic farm helps the chef to produce and present the best quality food to the guests

$>$ Appearance: Hydroponics enhances the customers experience in the restaurant by adding live greenery to the surroundings

$>$ Yield: Hydroponics is a modern method of growing plants.

Resources utilized for the growth of the plants through this system is much less than that of the traditional way.

This system focuses on providing nutrients directly to the plant roots; this increases the yield margin of the plants.

\section{HYDROPONIC FARM SETUP IN A HOTEL}

The setup of the hydroponic farm in a hotel mostly depends on its purpose. It can be placed in corridors for attraction and appearance, the farm can be setup on the rooftop of a building if the management needs it for cultivation of crops. As the initial investment is high in the setup of this plant the growers choose the rooftop cultivation as that would increase both the produce and the profits. The hydroponic farms must require a chamber style setup for the plants to increase the production space even further, vertical chambers are also advised. The farm must be installed with continuous water supply, thorough ventilation, adequate lighting (natural and grow lights) and required amount of nutrients. The above causes makes the rooftop of a building one of the best areas to set up the hydroponic farm Fairmont Singapore and Swissôtel The Stamford released the industry's first city aquaponics lawn in efforts to fulfill the growing demand amongst visitor for sparkling exceptional produce and to guide Singapore's intention of generating $30 \%$ of its dietary wishes domestically via way of means of 2030 .
The aquaponics answer at Fairmont Singapore and Swissôtel the Stamford is the end result of months of cautious and thorough research, searching at the quality viable manner to fulfill demand amongst visitors and customers for sparkling food; optimize limited area for developing produce; and to keep water and minimize water wastage.

\section{Environmental Benefits of Hydroponics}

We must also consider the significant environmental benefits of hydroponics. Hydroponics system requires only around $10 \%$ of the water that soil-based agriculture requires. This is because the hydroponic setup and the system allow the grower to recycle and reuse the water and nutrient solutions.

This can have quite an impact on areas where water is scarce. It is almost the same with the use of pesticides, hydroponics requires very little almost no pesticides to grow plants and moreover it requires only $25 \%$ of the nutrients and fertilizers that of the soil based plants. This means that the usage of chemicals is also very low and reduces the release of other unwanted chemicals into the air.

\section{CONCLUSION}

The study mainly focuses on the working of Hydroponics and the need of it for Indian hotels. The main purpose of the research was to know about Hydroponics in depth and the working process of the system. Hydroponics is truly the future of farming and also the Agricultural sector because of many factors. Limited use of resources, pesticide free growing, utmost utilization of space, faster production is few factors making the method a booming business. Most of the micro greens available around the worlds' hotels and restaurants are produced by this method. The utmost important need for hydroponics is its ability to produce all food crops round the year.

\section{REFERENCES}

[1]. Gericke, William F.(1937). "Hydroponics - crop production in liquid culture media". Science.85 (2198):177-178.

[2]. Dos Santos J.D (2013). "Development of a vinasse nutritive solution for hydroponics". Journal of environment management.114: 8-12

[3]. Gericke, William F. (1945). "The meaning of hydroponics". Science. 101(2615) 142-143

[4]. Jones, Jr. J.B (2004). Hydroponics: A Practical Guide for the soilless grower (2nd Ed.)Boca Raton, London, New York, Washington, D.C. pp 153-166

[5]. Gericke, William F. (1938). "Crop production without soil" 536-540

[6]. Namasivayam, C; Sangeetha, D. (January 2008). "Application of coir pith for the removal of other anions from water". Desalination. 219(1-3): 1-13 
[7]. Adania, Fabrizio; Genevinia, Pierluigi; Zacheoa, Patrizia; Zocchia, Graziano (1998). "The effect of commercial humic acid on tomato plant growth and mineral nutrition”. Journal of Plant Nutrition .21 (3): 561-575.

[8]. Kumar, Ramasamy Rajesh; Cho, Jae Young (2014) "Reuse of hydroponics waste solution". 9569-9577

[9]. Ritter, E,: Angulo, B.: Riga P.; et al (2001). "Comparison of hydroponics and aeroponic cultivation system for the production of potato minitubers". 127-135.

[10]. Barrett, G.E; Alexander, P.D. Robinson, J.S; Bragg, N.C (Nov 2016). Achieving environmentally sustainable growing media for soilless plant cultivation system- Scientia horticulturae. 212: 220234. 